\section{FOURTEENTH ANNUAL NESTBOX REPORT OF THE BRANDON JUNIOR BIRDERS}

\author{
by JOHN LANE* and \\ TONY BURTON**
}

In contrast to the year before, the winter of 1973-74 proved to be very severe and we set out less than 100 new nestboxes before the roads became impassable. In the spring of 1974 we got a few more out plus 100 rebuilds and we took another 100 up to Jim Spear at Russell, Manitoba, in mid-May to bring our overall total to 4,355 nestboxes in operation. Also, a start was made in moving nests from the TransCanada Highway to new locations, as that highway is to be double-laned between Brandon and Portage La Prairie and we had been advised that our nestboxes should be moved out of the way while the work is done.

1974 was not a very successful year for nesting bluebirds. An extremely cold and late spring kept birds from a normal start in their egg laying and we found a larger than usual number of clutches of abandoned eggs. Even where nestings were successful, the number of unhatched eggs set a new record; it was a common occurrence to find only two, three or four young in a nest of Mountain Bluebirds, where in other years it would have been four, five, six, or more. In addition, 1974 was plagued by a recurrence of black flies (Simulium venustum) and most of the first broods in the areas south and west of Brandon suffered severely from these swarming demons. Our experiences with black flies in 1970 and 1972 had prepared us for this year's invasion in that we had enlisted the help of the Department of Agriculture,

*1701 Lorne Avenue,

Brandon, Manitoba.

**2363 Brandon Avenue,

Brandon, Manitoba.
Winnipeg: A. J. Kolach of that depart ment came out to Brandon to give aic and advice. He furnished a quantity of chemical strip which is effective against insects, but because of our ignorance as to how large a piece we dared place in a nestbox, the product was ineffective this year. By the time the flies finished swarming we estimated a loss of 500 young bluebirds.

On the brighter side, Ed Robinson of Wawanesa reported the best year yet on his "Southeast Line". Art Michie and his "Southwest Line" around Souris were in the black fly country but second-broods were very good. Jim Spear at Russell expanded his lines further into the Assiniboine valley northwest of town and, in addition to a fine year with Mountain Bluebirds, had no less than eight Eastern Bluebird nestings. Saskatchewanites please take note, since these birds were at their very door.

The early summer was enlivened by a visit from Dr. D. Krieg of State University, New York. Dr. Krieg has made several trips to Brandon during the past years to study the interspecific actions and attitudes of the two bluebird species, with particular interest in the whys and hows of crossbreeding. Dr. Krieg took back with him two young from the first of three such nestings we found this year: the first from Clariere with just the two young, a second in the wildlife refuge area south of Hooke's Ranch, and the third just west of Sidney on the C.P.R. The first and third were the rare Mountain male $x$ Eastern female cross.

We had hoped to have a really good year of banding and had set a goal of 3,000 bluebirds for this year, but due to several reasons we fell short, only 2,361 being actually banded. By means of a $80 \%$ check, $20 \%$ estimate, we have arrived at the following totals for 1974 nestings: Mountain Bluebird 
(first broods only) 950; Eastern Bluebird (first broods) 160; Crossbred Bluebirds 3; Tree Swallow 2,550; House Sparrow 400; House Wren 40; deer mouse 100; red squirrel 10; Starling 5.

\section{INDIAN HEAD BLUEBIRD TRAIL REPORT — 1974}

\section{by LORNE SCOTT*}

After a long drawn-out winter with a record amount of snowfall, spring finally arrived in mid-April. The peak migration of Mountain Bluebirds was about 2 weeks later than usual and consequently nesting didn't begin until mid-May.

On May 18 a 5-day rain began and temperatures remained in the $40^{\circ} \mathrm{F}$ range. This prolonged wet and cold spell caused many of the female Mountain Bluebirds to abandon their nests in order to find enough food to stay alive.

When the weather finally did clear and become warmer, the bluebirds returned to the nest boxes. Some of the females began incubating the cold eggs but in most cases only two or three hatched from the clutch of six. Many of the bluebirds simply built another nest over the cold wet eggs and laid a new clutch.

Despite the poor start early in the nesting season, a record number of Mountain Bluebirds was raised in the nest boxes. One hundred female bluebirds were captured and banded while incubating eggs. Another 30 females which were caught were already wearing bands from the previous 4 years. Two of these females had been banded as adults in 1970, which means they are at least 5 years old, a ripe old age for a wild bird of

*Box 995 ,

Indian Head, Saskatchewan.

SOG $2 \mathrm{KO}$. this size. None of the bluebirds banded in 1969 were caught this year. A total of 800 young bluebirds were banded between May 28 and August 11 .

Tree Swallows also had another successful nesting season. Some 200 females and 1,600 young were banded. However, the success of Tree Swallows would be nearly doubled if House Sparrows could be eliminated along the trail.

One of the highlights this year was having a partial albino female Mountain Bluebird nesting. Her beak was white instead of black and the feathers on her head and back of her neck were pure white rather than the normal blue-grey colour.

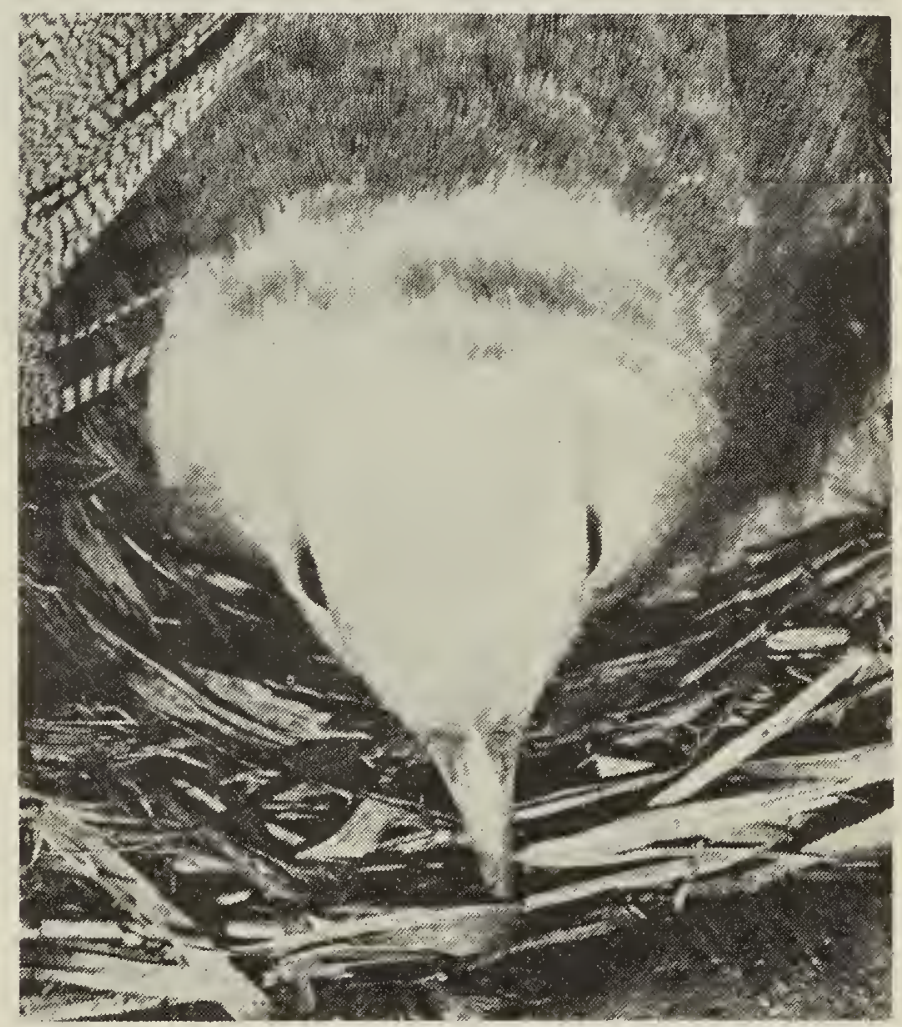

Lorne Scott

Partial albino female Mountain Bluebird at Indian Head, Saskatchewan. May 26, 1974.

Another first for this year was having a pair of Tree Swallows hatch and raise a Mountain Bluebird. Each year two or three bluebird nests are taken over by swallows while the bluebirds are laying eggs. The Tree Swallows lay their eggs in the nest containing one or more bluebird eggs. Usually the bluebird eggs hatch along with those of the swallows. However, 